\title{
A Comprehensive Study of the Acoustic Properties of Metal Meshed Reinforced Sustainable Foam
}

\author{
Kunal Yadav*, Akansh Vishwakarma*, Sakshi Agarwal**, Asim Sneh*, Manshu Gupta* \\ *B. Tech Mechanical Engineer, SMEC, \\ Vellore Institute of Technology Chennai, Tamil Nadu - 600127 \\ ${ }^{* *}$ B.Tech Metallurgical and Materials Engineer, \\ MNIT Jaipur, Rajasthan - 302017
}

\begin{abstract}
Organic foam with copper, brass, iron and steel mesh reinforcement are prepared. Acoustic shielding test, yielding Sound absorption coefficient of the samples is performed. The reinforced samples showed better result than normal foam especially in lower frequency range. Foam with brass and steel mesh reinforcement showed the best sound absorption capability among all of the samples at the lower frequency of $200-250 \mathrm{~Hz}$. The SEM result testified that the holes in the reinforced samples are discontinuous causing energy loss of the sound wave and thus imparting better sound absorption capabilities to them.
\end{abstract}

\section{Keywords-Acoustic shielding, frequency range, sustainable flexible foam, sound absorption capability, SEM analysis.}

\section{INTRODUCTION}

In today's era, noise is among the most pressuring issues of our society. Any unwanted and excess sound around us is called Noise. If the level of noise can be reduced, it can become an application of high significance. Hearing loss is just a singular problem of these outlandish disturbance levels. It can intrude in day to day life and can cause trouble and non-sound related issues [1-3]. Adding to it, if present in huge degrees, it can lead to essential dis-functioning and degradation in life of mechanical equipment's. For example, in case of control valves, the vibration due to the irregular flow of stream can cause hindrance with the feedback system of the control unit and can result in severe oscillations.

The need for reduction in noise and vibration level could be clearly realised by looking at rules that have been laid by governments to restrain disturbance created by this. The present-day contraption, air/surface transportation, and improvement practices are believed to be the standard supporters of upheaval creation or assumed "uproar tainting" [4]. Right now, lightweight and pocketfriendly composite materials that will acclimatize sound waves in increasingly broad frequency range are essentially needed. In the current scenario, by a wide margin, a large portion of acoustic material is conveyed using produced strands which are risky to human health condition [5]. Thus a eco-friendly material is needed and common foam can be one such solution. In this research paper, organic foam is developed and analysed for its acoustic characteristic. The advantages of using regular foam are that it is low density material, versatile and hazard free. We have used various tests to various properties of the material. With the help of Acoustic ensuring test Setup, acoustic securing limit of the material was calculated. Earth-wide temperature support is another huge [6] issue with racket defilement, right now, is an essential of an adaptable material which has an extraordinary sound ingestion coefficient just as is an awful conductor of warmth so it shields a bound space from upheaval just as from warmed outside. PU Foam is a heat insulator [7]. Regardless of way that PU froths, it has sufficient quality [8] for the present applications. Its quality can be regulated by layering of mesh with different materials and number of layers. The fabricated material can be used for applications varying from sound insurance material for dividers of structures or vehicles to internal securing material of planes and space transports. We can achieve maximum absorption at resonance over the broadest possible range by measuring specific acoustic impedance in an impedance tube [9], [10], [11]. In this experiment, five samples are fabricated, one among which is an organic foam without additives, and four are flexible foams with different mesh material incorporated in it as a filler layer. Even after having various properties, the gathering cost of the material is humble and manufacturing is simple and fast. With its nonhazardous nature, versatility, and reasonable cost it is a great material with an astoundingly colossal extent of uses.

\section{A. Fabrication of Meshed foams}

\section{EXPERIMENTAL PROCEDURE}

Five samples are fabricated, one among them is a sustainable organic foam without mesh reinforcement, other four sustainable organic foam with different mesh samples have been prepared with single layer of Copper, Brass, Iron and Steel meshes of grid size $1 \mathrm{~mm}$ reinforced in flexible foam. Wooden and aluminium boxes with top side open are made to carry out the foam forming reaction. The boxes are mounted with fixtures to hold the mesh in the middle of the foam. Once the mesh is fixed in the mold, a blend of isocyanides and synthetic polyol are mix together in a ratio of $2: 3$. The nature of the reaction is exothermic with release of $\mathrm{CO}_{2}$ fumes as shown in fig $1,2,3$ respectively [12]. 


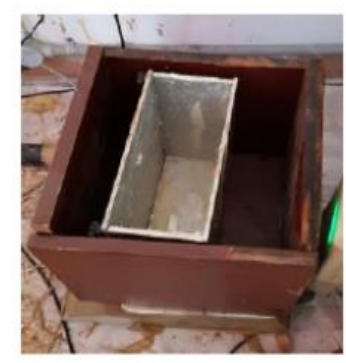

Fig. 1. Mould for foam Fabrication

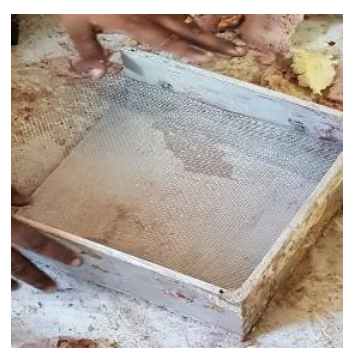

Fig. 2. Al waxed tray mold for material.

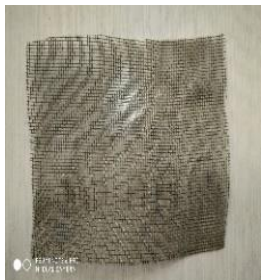

(a) Brass

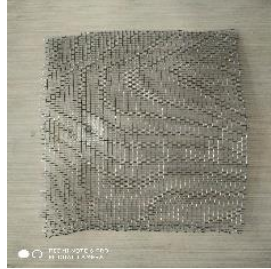

(c) Steel

(c) Steel Iron
Fig. 3. Metal meshes reinforced in foam

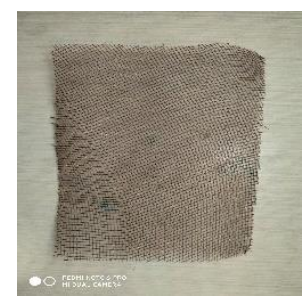

(b) Copper

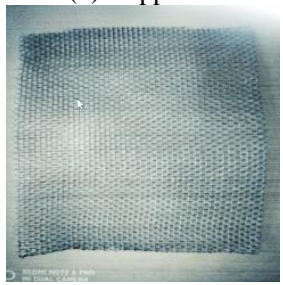

(d) Iron

B. Experimental analysis of Acoustic Shielding of different materials Setup

Sound absorption coefficient can be defined as some part of energy of sound absorbed in a given frequency band by the sample incident with a sound wave. It indicates the capability of the sample to absorb the sound over a given range of frequency bandwidth. Impedance tube apparatus is used for measuring the sound absorbing capacity of a material. The characterizing system consists of a solid glass tube in which a speaker is embedded at one end and the sample is hold inside a cylindrical vessel at the opposite side as shown in fig 4 . The framework likewise has a couple of sound receivers that are connected to the digital signal analyser via pre-amplifiers and a DAQ. Its powered by a function generator and also has a rigid backing. The specifications and schematics are shown below in fig 5,6,7,8 and table 1 respectively. [11]

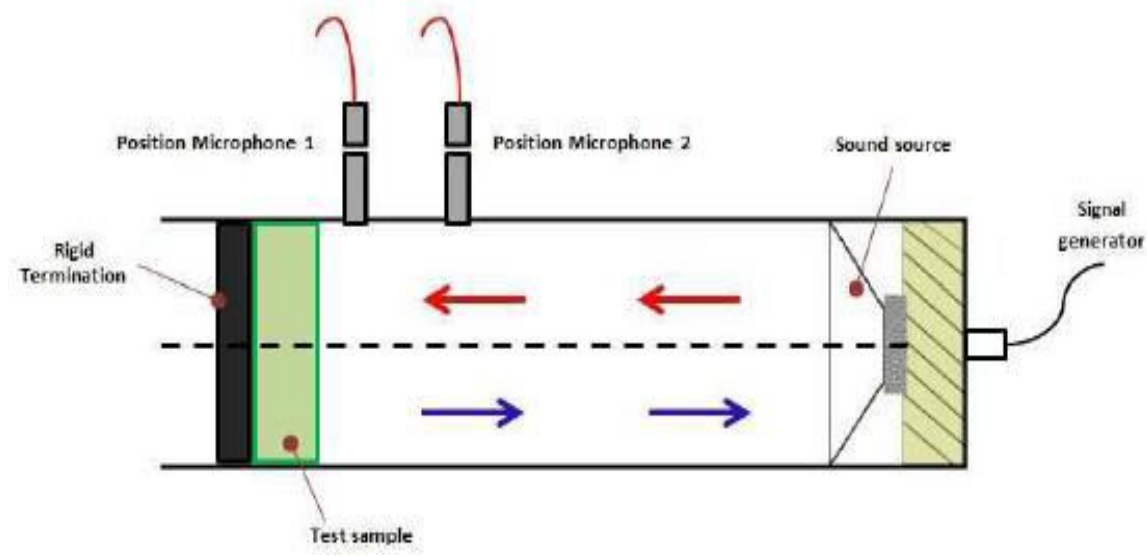

Fig. 4. Schematic of Impedance Tube Apparatus

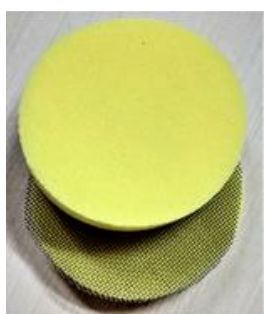

Fig. 5. Cross section view of Test Sample

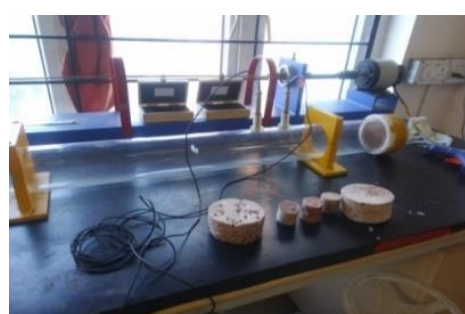

Fig. 6. Impedance tube Test Setup 


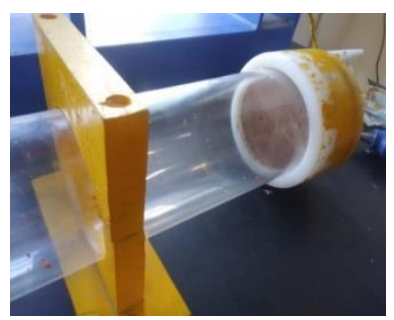

Fig. 7. Sample in the impedance tube

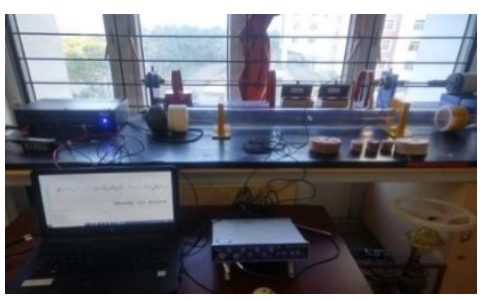

Fig. 8. Spectrum Analyzer

\begin{tabular}{|c|c|}
\hline Parameter & Specification \\
\hline Impedance tube length & $900 \mathrm{~mm}$ \\
\hline Inside diameter & $56 \mathrm{~mm}$ \\
\hline Speaker frequency response range & $160-7000 \mathrm{~Hz}$ \\
\hline Signal generator & $200-6500 \mathrm{~Hz}$ \\
\hline Sweep in & Automated \\
\hline Number of microphones & 2 \\
\hline Sample holding unit & $50 \mathrm{~mm}$ \\
\hline Controls & PC automated measurements \\
\hline Software & MATLAB \\
\hline
\end{tabular}

\section{A. FTIR characterization}

As indicated in the below graph from the Fourier Transformation Infrared (FTIR) Spectrum we can easily characterize the presence of different functional groups present in the sample. The plot obtained is shown in fig.9.

- Flexible foam: In the following graph below, we can see that broadens occurs in the range near $3500 \mathrm{~cm}^{-1}$ which indicates the presence of $(-\mathrm{OH})$ functional group. Also the peak sharply stretches in range $3000 \mathrm{~cm}^{-1}$ which indicates the presence of (-C-H) group. Moreover, the absorption ranging between $2165-2110 \mathrm{~cm}-1$ shows the indication of cyanide functional $(-\mathrm{CN})$ group.

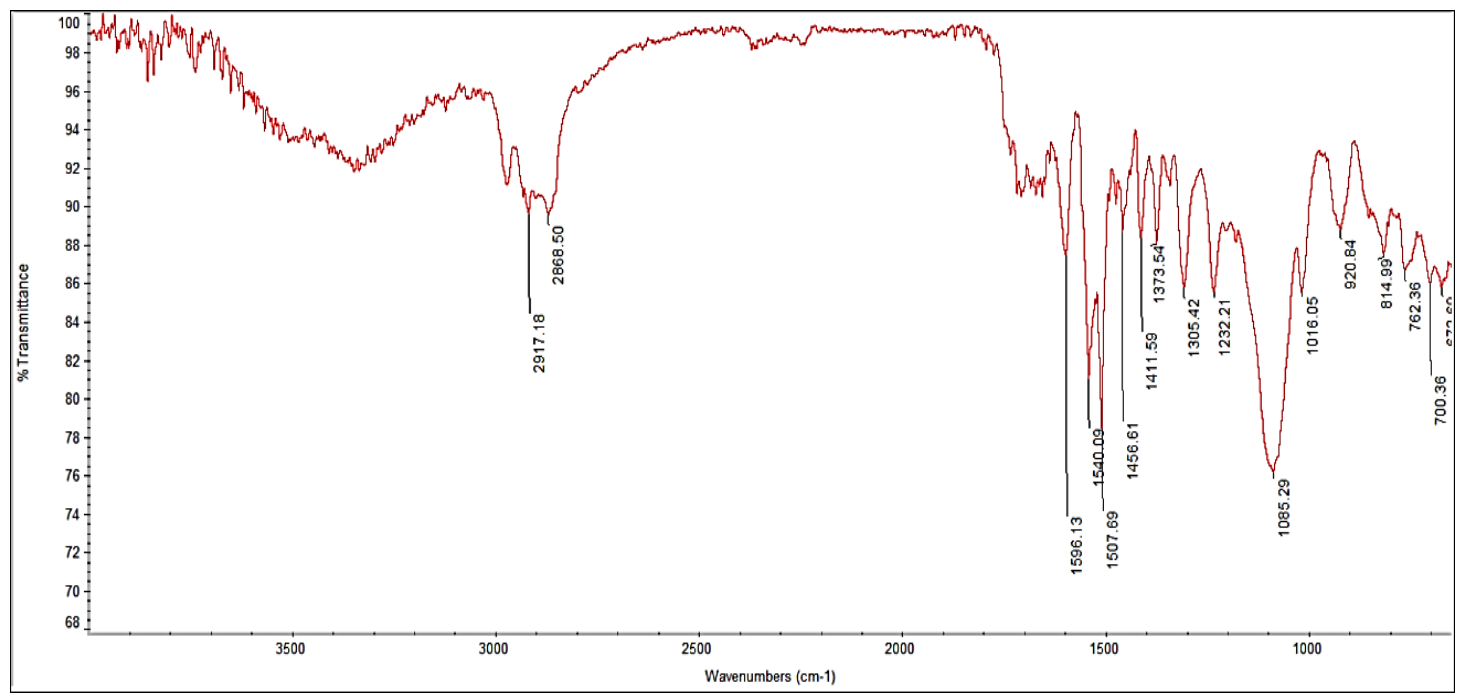

Fig. 9. FTIR characterization of flexible foam 
B. Experimental analysis of Acoustic Shielding of different materials:

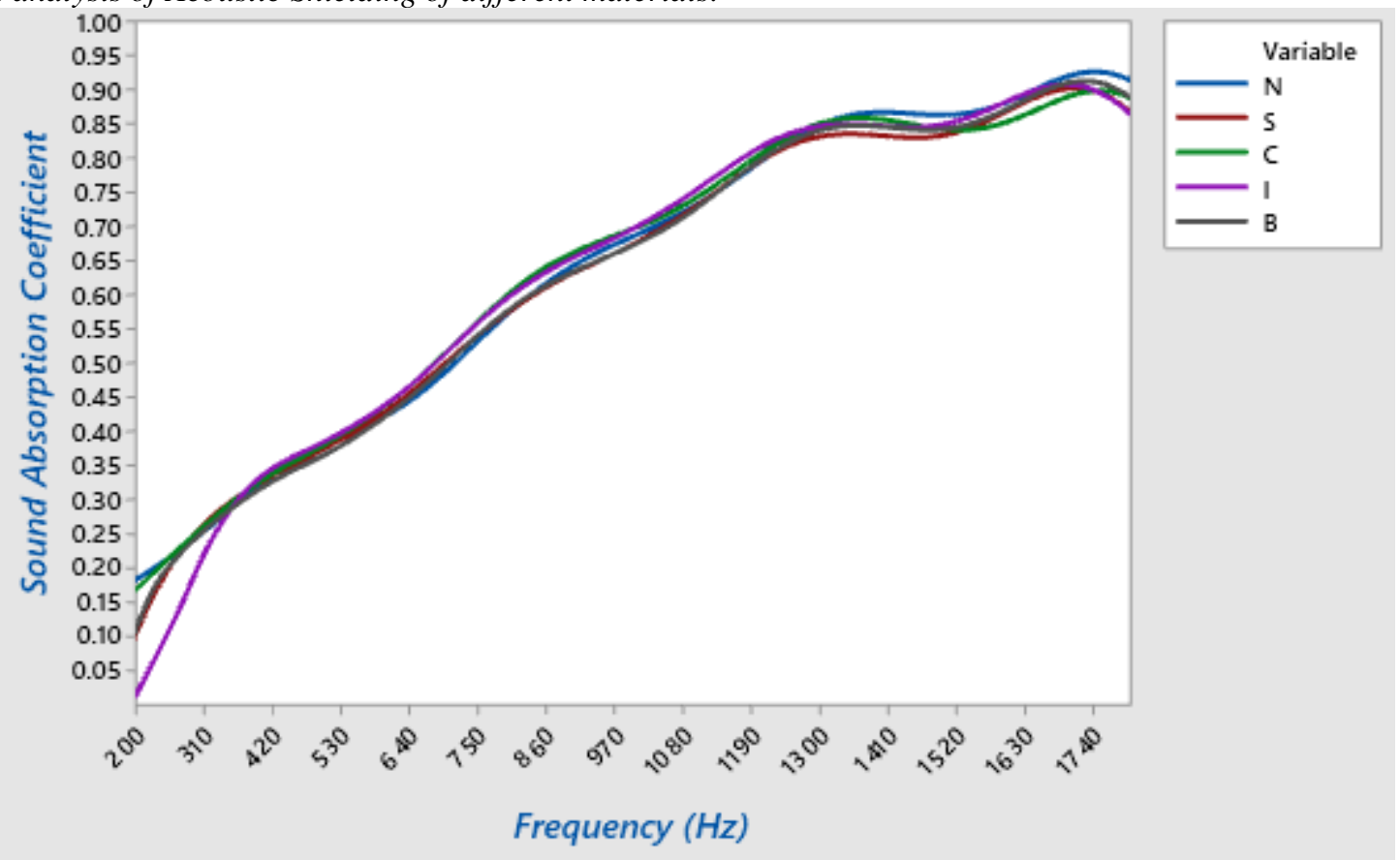

Fig. 10. Comparison of Sound Absorption capability of different meshed foams

Result obtained from the Acoustic Shielding Test is represented in the form of a graph as shown in figure 10 and has also been summarized in Table 2. It is found that the mesh reinforced foam shows better sound absorption coefficient than the normal foam. We observed improvement in the sound absorption coefficient after reinforcement especially in the lower range of frequency.

Table 2. Test Observations of Sound Absorption Coefficient

\begin{tabular}{|c|c|c|c|c|c|}
\hline SAMPLE $\rightarrow$ & $\mathbf{S}$ & $\mathbf{C}$ & $\mathbf{I}$ & $\mathbf{B}$ & $\mathbf{N}$ \\
\hline $\begin{array}{c}\text { FREQUENCY } \\
(\mathbf{H z})\end{array}$ & \multicolumn{5}{|c|}{ SOUND ABSORPTION COEFFICIENT } \\
\hline $\mathbf{2 0 0}$ & 0.1677 & 0.1546 & 0.1014 & 0.2072 & 0.0570 \\
\hline $\mathbf{2 5 6}$ & 0.2675 & 0.1822 & 0.2330 & 0.2578 & 0.0859 \\
\hline $\mathbf{3 2 0}$ & 0.2703 & 0.2759 & 0.2764 & 0.2871 & 0.2590 \\
\hline $\mathbf{4 0 0}$ & 0.3587 & 0.3578 & 0.3156 & 0.3310 & 0.2973 \\
\hline $\mathbf{5 0 4}$ & 0.3822 & 0.4025 & 0.4024 & 0.3845 & 0.4015 \\
\hline $\mathbf{6 3 2}$ & 0.4942 & 0.4644 & 0.4279 & 0.4913 & 0.4455 \\
\hline $\mathbf{8 0 0}$ & 0.5881 & 0.600 & 0.6162 & 0.5603 & 0.5619 \\
\hline $\mathbf{1 0 0 0}$ & 0.6684 & 0.6790 & 0.6959 & 0.6483 & 0.6763 \\
\hline $\mathbf{1 2 5 6}$ & 0.8418 & 0.8565 & 0.8569 & 0.8452 & 0.8228 \\
\hline $\mathbf{1 6 0 0}$ & 0.8658 & 0.8738 & 0.8812 & 0.8563 & 0.8326 \\
\hline $\mathbf{1 8 0 0}$ & 0.9009 & 0.9259 & 0.8913 & 0.9338 & 0.8505 \\
\hline
\end{tabular}


C. Scanning Electron Microscopy Analysis

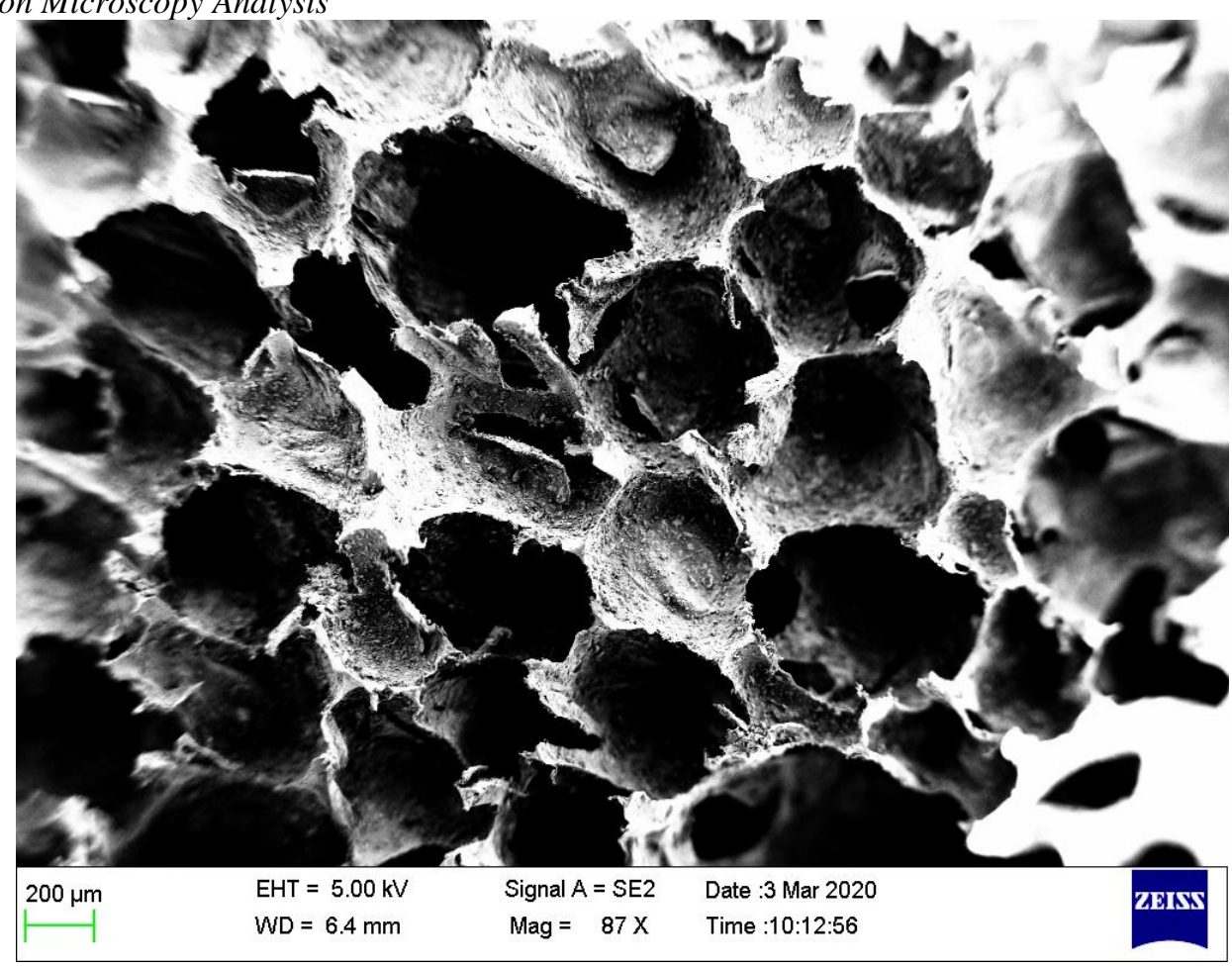

Fig. 11. SEM (87X)

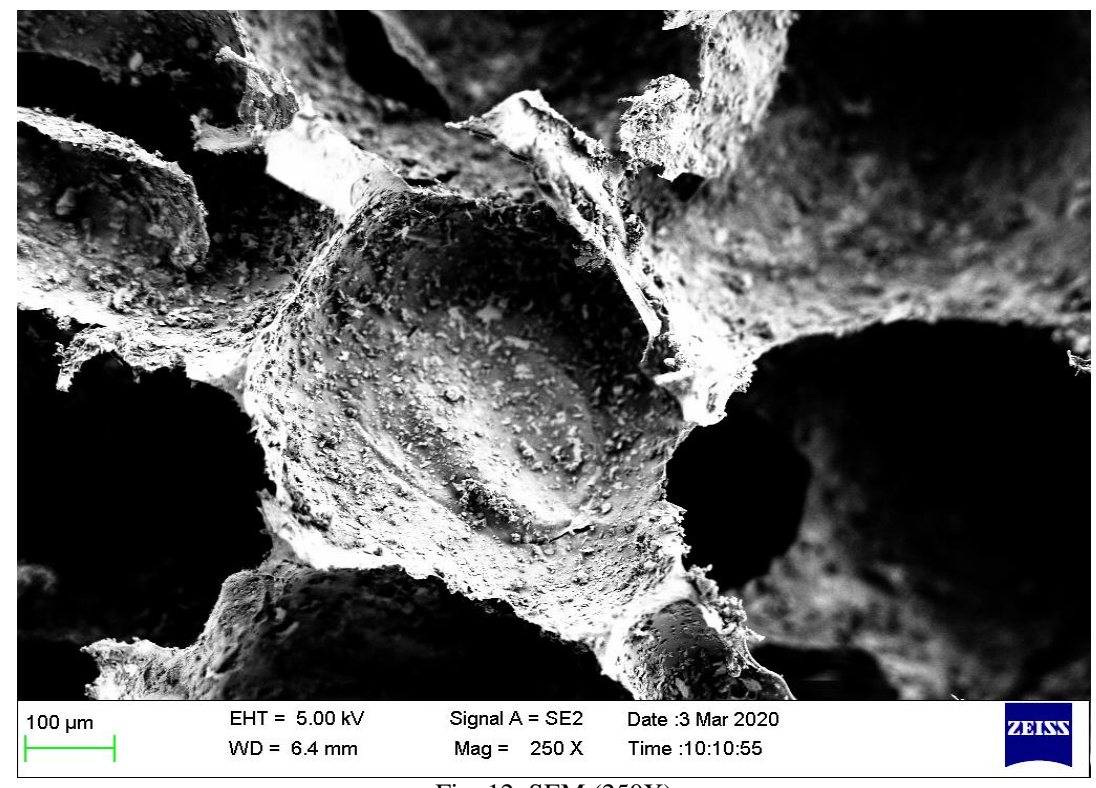

Fig. 12. SEM (250X)

Above figures 11,12 were obtained from SEM analysis of the foam. It was found that there are more discontinuous holes in the mesh reinforced samples than normal foam. This discontinuity causes energy loss in the sound wave making sound absorption coefficient more for the reinforced foam.

\section{CONCLUSION}

$>$ The capability of sound absorption by the material is characterized using the Acoustic Shielding Performance Test and FTIR test is used to characterize the chemical structure of the sample.

$>$ It was found that the mesh reinforced samples showed better Sound Absorption Coefficient than the normal foam especially in low frequency range.

$>$ Sample with Brass mesh showed the best sound absorbing among all the samples in the frequency range of 200-250 Hz.

$>$ The SEM pictures showed that the holes in the reinforced foam were more discontinuous than the normal foam thus enhancing loss of energy in the sound waves and making them more effective in sound absorption.

$>$ Due to reinforcement of the foam its shape retaining ability and strength increased thus making it more prominent candidate in the use of real life applications. 


\section{NOMENCLATURE}
S: PU Foam with steel mesh reinforcement.
C: PU Foam with copper mesh reinforcement.
I: PU Foam with iron mesh reinforcement.
B: PU Foam with brass mesh reinforcement.
$\mathrm{N}$ : PU Foam with no reinforcement.

\section{REFERENCES}

[1] Alam, J.B., Jobair.J. Rahman.M.M, Dikshit. A.K. and Khan S.K. Study on traffic noise level of sylhet by multiple regression analysis associated with health hazards\|, Iran. J.Environ. Health. Sci.Eng., 2006; 3(2):71-78.

[2] Murthy,V.K., Khanal, S.N., Assessment of traffic noise pollution in Banepa, a semi urban town of Nepal, Kathmandu university,Journal of science, engineering and technology, 2007;1:1-9

[3] Ohrstrom, E., Bjorkman, M., and Rylander, R., "Subjective Evaluation of Work Environment with Special Reference to Noise", Journal of Sound and Vibration, Volume 65, No. 2, pp. 241-249, 1979.

[4] Bhatt, S.R., Subrahmanyam, K., and Swami, K.R., "Noise Pollution in Textile Industry", A Review Report by ATIRA, Ahmedabad, 1990

[5] Sound absorption analysis of castor oil based polyurethane foamwith natural fiber, Yuvaraj.La ,S.Jeyanthi*a, M.C.Lenin Babua ,a Vit University Chennai Campus-600127,India.

[6] Schellnhuber, H. J. (2008). Global warming: Stop worrying, start panicking? Proceedings of the National Academy of Sciences, 105(38), 1423914240.doi:10.1073/pnas.0807331105

[7] Tseng, C., Yamaguchi, M., \& Ohmori, T. (1997). Thermal conductivity of polyurethane foams from room temperature to 20 K. Cryogenics, 37(6), 305-312.doi:10.1016/s0011-2275(97)00023

[8] Sparks, L.L. and Arvidson, J.M., Thermal and mechanical properties of polyurethane foams and a survey of insulating concretes at cryogenic temperatures. Report NTIS PB85-100949, National Bureau of Standards, Boulder, CO, 1984

[9] LIN Lei,WANG Zuo-min,JIANG Zai-xiu, Effects of absorbing wall on acoustical property of micro-perforated panel absorbers

[10] W. A. DAVERN, Perforated Facings Backed with Porous Materials as Sound Absorbers--An Experimental Study.

[11] Manshu Gupta, Asim Sneh, Jeyanthi Subramanian, Yuvaraj L., 2019, An Experimental Investigation on the Acoustic and Thermal Properties of Copper Reinforced Sustainable Foam, INTERNATIONAL JOURNAL OF ENGINEERING RESEARCH \& TECHNOLOGY (IJERT) Volume 08, Issue 08 (August 2019),

[12] Asim Sneh, Prem Thakur, Kunal Yadav, Ritesh Goyal, Manshu Gupta, 2020, An Experimental Analysis of EMI Shielding Effectiveness using Multi layered Metal Meshed Reinforced Sustainable Foam, INTERNATIONAL JOURNAL OF ENGINEERING RESEARCH \& TECHNOLOGY (IJERT) Volume 09, Issue 02 (February 2020).

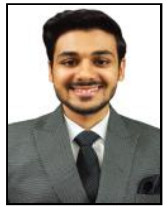

\section{AUTHOR'S PROFILE}

Kunal Yadav: B.Tech Mechanical Engineer, School of Mechanical Engineering Chennai (SMEC), Vellore Institute of Technology Chennai. Research areas are Carbon Fibre Composites, EMI sheilding and Acoustic properties of materials. Published 1 articles in reputed international journals.

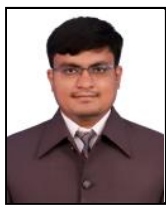

Akansh Vishwakarma: B. Tech Mechanical Engineer, School of Mechanical Engineering Chennai (SMEC), Vellore Institute of Technology Chennai. Research areas are Materials, Thermodynamics, EMI and Automotive Technologies.

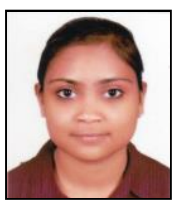

Sakshi Agarwal: B.Tech Metallurgical and Materials Engineering, Malaviya National Institute of Technology, Jaipur. Research areas Composite fabrication and analysis, Electrical and Physical Properties characterization of newly developed materials.

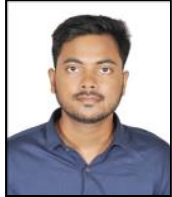

Asim Sneh: B.Tech Mechanical Engineer, School of Mechanical Engineering Chennai (SMEC), Vellore Institute of Technology Chennai. Research areas are Heat Transfer,nanopaticles and nanofluids, EMI and acoustics materials development. Published 2 articles in reputed international journals.

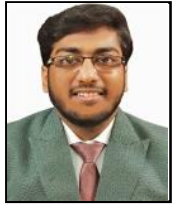

Manshu Gupta: B.Tech Mechanical Engineer, School of Mechanical Engineering Chennai (SMEC), Vellore Institute of Technology Chennai. Research areas are IC engines, Heat transfer, nanopaticles, EMI and acoustics materials development. Published 3 articles in reputed international journals. 